information which is now so readily available elsewhere that such an extensive table scarcely seems necessary. A few minor blemishes have been noted : for example, inelastic scattering of neutrons can but rarely be an exothermic process (p. 208) ; increasing the time-constant can scarcely reduce the time of response of a rate-meter (p. 188) ; and the definitions given (p. 274) for "roentgen-equivalent-physical" and for "roentgen-equivalent-man" are distinctly misleading. None of these points, however, is really fundamental, and the general standard of accuracy is very high.

The production of the book is well up to the standards expected of the Oxford University Press, and the price, although higher than one might have wished, is certainly not unreasonable. The book should have an assured place in the growing literature of radiochemistry and should, moreover, be of considerable use to biologists and others interested in radioactive tracer methods. G. R. MARTiN

\section{WAVES AND TIDES}

Waves and Tides

By R. C. H. Russell and Comdr. D. H. Macmillan. Pp. 348+17 plates. (London: Hutchinson's Scientific and Technical Publications, 1952.) 25s. net.

1 THE connexion between waves and tides, clear enough to the physicist, is apparent also from the practical point of view. The effects of both concern the mariner and harbour engineer and are of interest to the seaside visitor, to whom this book is also addressed. Our knowledge of tides has reached a comparatively advanced stage, largely because of their regular nature and their dependence on known astronomical factors. Although the basic theory of waves was developed more than a century ago, reliable observations were scanty until the outbreak of the Second World War, owing to the difficulties of measuring such irregular phenomena, especially from a ship at sea. War requirements gave an impetus to the development of better measuring instruments, providing more observations which, in turn, have pointed to new theoretical problems.

In this book the subjects of waves and of tides have been treated separately by the two authors. Mr. R. C. H. Russell begins Part 1 by describing the characteristics of ocean waves and outlining the methods by which these have been determined. A concise account is given of the classical theory of waves in deep water, the changes whiah they undergo on approaching $a_{0}$ shore, and the effects of reflexion, refraction and diffraction. The way in which waves are generated by wind has been the subject of recent researches and is still largely an unsolved problem. Turning from the waves themselves to their action in moving material and their effects on structures, the author includes much recent work, particularly on models. One is made aware of how many doubtful points and conflicting ideas there are in this field, and of the need for more research, especially of a fundamental character.

Commander D. H. Macmillan introduces Part 2 with a historical and descriptive account of tides, and then gives an account of the general features of the equilibrium theory. The next chapter is concerned largely with the natural and forced oscillations of bodies of water, and shows how the theory of such oscillations may be combined with the equilibrium theory to explain the features of tides as they actually occur. Subsequent chapters deal with more practical aspects, such as the prediction and recording of tides and tidal streams and the prospects of any large-scale use of tidal power. The short chapter on "Tides and the Weather" touches on a subject which has assumed greater topical interest since the book was published. The disturbance of tidal levels by storm surges and wind effects is one of the outstanding problems of tidal research to-day. An unfortunate number of misprints occur in the equations throughout Part 2, including two in the summary of formulæ on p. 334 .

The authors have performed a valuable service in producing a book which presents the results of recent researches on waves and tides against a background of more firmly established knowledge.

K. F. BOWDEN

\section{FRESHWATER ALG/E OF ILLINOIS}

The Algæ of Illinois

By Lewis Hanford Tiffany and Max Edwin Britton. Pp. xiv + 407. (Chicago: University of Chicago Press ; London : Cambridge University Press, 1952.) $75 s$, net.

GRESHWATER Algæ have been intensively $F$ studied in many parts of the United States during the present century, and the rich and diverse character of this flora has been suitably epitomized in G. M. Smith's "Freshwater Algæ of the United States", now in its second edition. Tiffany and Britton's "Algæ of Illinois" deals with only a single State of the Union, covering an area larger than that of England, and takes the form of a flora with keys for the determination of genera and species and diagnoses and figures of the nearly 1,200 species so far recorded. It thus constitutes a work that is of considerable local value which will serve as a stimulus to those continuing with the task of exploration. For them some reference under each group to standard taxonomic works would have been helpful.

In such a local flora, dealing with a region which is still in many respects quite imperfectly explored, it is inevitable that the representation of different groups is unbalanced. Some, like the Oedogoniales and Zygnemales which have been specially studied in the area concerned, are represented by numerous species ; but for others the records are meagre. Thus, large genera like Chlamydomonas and Carteria are each represented by only a single species, only three species of Euastrum and one of Arthrodesmus are recorded, while such a widespread epiphyte as Chamoesiphon is lacking. This inequality must, of course, detract from the value of the flora to workers in other areas and raises the question whether it is advisable to publish a manifestly incomplete record in so ambitious a form. It is to be regretted that the authors have omitted to give adequate habitat data for most species, sinoe the value of a local flora to those working elsewhere depends largely on the geographical and ecological facts that can be gleaned from it.

The copious and for the most part clear illustrations, grouped in 108 plates, contribute much to the general usefulness of the work. A proportion of the figures are original, some of them of a somewhat diagrammatic type which is not always very informative, as, for example, those depicting Phacotus lenticularis.
F. E. Fritsch 